\title{
SISTEM PENUNJANG KEPUTUSAN PEMILIHAN KARYAWAN TERBAIK MENGGUNAKAN METODE SIMPLE ADDITVE WEIGHTING (SAW) PADA PT RINGKAT TEKNOLOGI MULIATAMA JAKARTA
}

\author{
Putro Sapno Pamungkas ${ }^{1}$ \\ Program Studi Sistem Informasi STIMIK Nusa Mandiri Jakarta \\ putropamungkas92@gmail.com \\ Yahdi Kusnadi ${ }^{2}$ \\ Program Studi Sisttem Informasi Akuntansi Universitas Bina Sarana Informatika Jakarta \\ yahdi.ydk@bsi.ac.id
}

\begin{abstract}
Abstrak - Salah satu komponen terpenting yang dimiliki dalam suatu perusahaan adalah karyawan. Dalam meningkatkan daya saing, perusahaan harus memiliki karyawan-karyawan yang terbaik. Sehingga setiap tahunnya perusahaan mempunyai karyawan terbaik agar dapat dipertahankan dan dapat bersaing dengan perusahaan lainnya. Berdasarkan hal itu, penelitian ini mencoba untuk memilih karyawan terbaik pada PT Ringkat Teknologi Muliatama dengan menggunakan sistem penunjang keputusan metode simple additive weighting, yang terdiri dari lima kriteria yaitu kehadiran, sikap kerja, kedisiplinan, prestasi kerja dan kerjasama. Pengambilan sampelnya adalah karyawan yang ada di PT Ringkat Teknologi Muliatama, karena pada perusahaan ini belum ada pemilihan karyawan terbaik setiap tahunnya. Penelitian ini mendapatkan sebuah kesimpulan bahwa karyawan yang bernama Ali Hidayat mendapat nilai terbesar sebesar 0,85 dan mendapatkan predikat sebagai karyawan terbaik pada PT Ringkat Teknologi Muliatama.
\end{abstract}

Employee

\section{Pendahuluan}

Salah satu komponen terpenting yang dimiliki dalam suatu perusahaan adalah karyawan. Perusahaan yang sudah memiliki karyawan didalamnya, maka perusahaan itu harus menilai karyawan dengan kinerja yang baik atau tidak. "Eksistensi seorang karyawan dalam menjalankan tugasnya sangat mendukung suatu pencapaian perusahaan.”(Kristiyanti, 2017). Karena dengan begitu terdapat kinerja karyawan yang baik, perusahaan dapat berkembang dan mampu bersaing.

"Persaingan di dunia bisnis yang makin kompetitif memacu perusahaan untuk berupaya lebih keras dalam meningkatkan kualitas perusahaannya" (Ritonga, 2013). Dalam hal untuk meningkatkan daya saing, perusahaan harus meningkatkan kinerja kerja pada setiap karyawan. Memberikan pelatihan-
Kata Kunci : Karyawan, Simple Additive Weighting, Karyawan Terbaik

Abstract - One of the most important components in the company is employees. In improving competitiveness, companies must have the best employess. All companies have various needs to be able to serve and can compete with other companies. Based on this, this study aims to select PT. Ringkat Teknologi Muliatama by using a support system. The method of determining simple weights which consists of five functions, namely position, work attitude, discipline, work performance and partnership. The sampling is the employees at PT Ringkat Teknologi Muliatama, because there is no best choise for this company every year. This Study found a conclusion that the employee named Ali Hidayat obtained the greatest value of 0,85 and became the best employee at PT Ringkat Teknologi Muliatama.

Key Word: Employee, Simple Additive Weighting, Best

pelatihan, kursus-kursus dan yang lainnya serta memberikan predikat karyawan terbaik.

"Oleh karena itu diperlukan suatu sistem pendukung keputusan (SPK) yang dapat memperhitungkan segala kriteria yang mendukung pengambilan keputusan guna membantu mempermudah proses pengambilan keputusan tersebut" (Murdianto, Khairina, \& Hatta, 2016). Dalam hal ini penulis menggunakan suatu metode yang dipakai untuk memilih karyawan terbaik, adalah metode Simple Additive Weighting (SAW). Metode Simple Additive Weighting (SAW) dipilih karena dari beberapa jurnal sudah terbukti berhasil menggunakannya diantaranya yaitu Sistem Pendukung Keputusan Pemilihan Karyawan Terbaik Per Triwulan Pt.Cahaya Fajar Kaltim Pltu Embalut Tanjung Batu Menggunakan Metode Simple Additive Weighting, 
Pemilihan Karyawan Terbaik Di PT Sehat Bahagia Keluarga Dengan Metode Simple Additive Weighting, dan yang lainnya.

Selanjutnya untuk menentukan karyawan yang terbaik maka diperlukan penilaian dari kriteriakriteria yang telah ditentukan. Untuk mendapatkan kriteria yang dijadikan sebagai acuan bisa melihat dari jurnal yang sudah ada seperti pada Penentuan Karyawan Terbaik Dengan Metode Simple Additive Weighting (PDAM Tirta Silaupiasa) karya Mahrizal Masri, memilih kriteria berdasarkan kualitas kerja, disiplin, semangat kerja, dan kerjasama. Sedangkan pada jurnal Sistem Pendukung Keputusan Pemilihan Pegawai Terbaik PT Pegadaian Jakarta Dengan Metode Simple Additive Weighting karya Aulia Fitriah memilih kriterianya berdasarkan kepemimpinan, efektitas produk, fokus pelanggan, fokus tenaga kerja, keuangan dan pasar, inovatif, nilai moral tinggi, terampil, adi layanan dan nuansa citra.

\section{Metodologi Penelitian}

\subsection{Simple Additive Weighting (SAW)}

Simple Additive Weighting Method (SAW) sering juga dikenal istilah metode penjumlahan terbobot. Konsep dasar metode SAW adalah mencari penjumlahan terbobot dari rating kinerja pada setiap alternatif pada semua atribut menurut Pahlevy (2010).

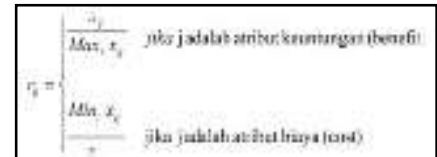

Sumber : Pahlevy (2010)

Gambar 1. Persamaan Formula Ternomalisasi

Keterangan :

a. Simbol rij adalah rating kinerja ternomarlisasi dari alternatif $\mathrm{A}$, pada atribut $\mathrm{C}, \mathrm{i}=1,2, \ldots, \mathrm{m}$ dan $\mathrm{j}=1,2, \ldots, \mathrm{n}$ ( $\mathrm{m}$ dan $\mathrm{n}$ merupakan banyaknya alternatif dan kriteria)

b. Simbol xij adalah nilai rating kecocokan pada Ai dan $\mathrm{Cj}$,

c. Simbol Max xij adalah nilai terbesar dari semua nilai rating kecocokan pada setiap kriteria.

d. Simbol Min xij adalah nilai terkecil dari semua rating kecocokan pada setiap kriteria.

e. Atribut keuntungan adalah jika nilai terbesar dalam atribut tersebut merupakan nilai terbaik,

f. Atribut biaya ada jika nilai terkecil dalam atribut tersebut merupakan nilai terbaik.

Nilai preferensi untuk setiap alternatif (Vi) diberikan sebagai berikut:

Sumber : Pahlevy (2010)
Gambar 2. Persamaan nilai preferensi untuk setiap alternatif

Keterangan:

a. Simbol Vi adalah rangking untuk setiap alternatif

b. Simbol $\mathrm{n}$ adalah banyaknya (jumlah) alternatif

c. Simbol $\mathrm{Wj}$ adalah nilai bobot dari setiap kriteria

d. Simbol rij adalah nilai rating kinera ternomalisasi

Nilai Vi yang lebih besar mengidentifikasikan bahwa alternatif $\mathrm{A}$, lebih terpilih

\section{Hasil Dan Pembahasan}

Metode Simple Additive Weighting (SAW) ini untuk melakukan perhitungannya diperlukan kriteriakriteria dan bobot agar nanti didapat nilai yang terbaik. Dalam hal ini manajer mengisi kriteriakriteria yang telah ditentukan yaitu nilai kehadiran, nilai sikap kerja, nilai kedisiplinan, nilai prestasi kerja dan nilai kerjasama.

Ada beberapa langkah melakukan perhitungan untuk menentukan karyawan terbaik menggunakan metode simple additive weighting (SAW).

1. Data Alternatif Calon Karyawan Terbaik PT Ringkat Teknologi Muliatama

Langkah yang pertama menentukan alternatif, yaitu $\mathrm{Aj}$ berikut adalah data alternatif yang akan digunakan dalam perhitungan.

Tabel 1. Data Alternatif

\begin{tabular}{|c|c|c|c|c|c|c|}
\hline \multirow{3}{*}{ No } & \multirow{3}{*}{ Data Karyawan } & \multicolumn{5}{|c|}{ Nilai Kriteria } \\
\hline & & Kehadiran & Sikap & Kedisi & i Prestasi & Kerjasama \\
\hline & & & Kerja & nan & Kejra & \\
\hline 1 & Ali Hidayat & 100 & 95 & 80 & 70 & 45 \\
\hline 2 & $\begin{array}{l}\text { Chandra } \\
\text { Briliandika }\end{array}$ & 90 & 50 & 85 & 80 & 70 \\
\hline 3 & $\begin{array}{l}\text { Yudha } \\
\text { Permana }\end{array}$ & 85 & 40 & 75 & 60 & 85 \\
\hline 4 & $\begin{array}{l}\text { Tegar A. } \\
\text { Sangaji }\end{array}$ & 75 & 90 & 75 & 35 & 75 \\
\hline 5 & $\begin{array}{l}\text { M. Andika } \\
\text { Fiqqi }\end{array}$ & 95 & 50 & 80 & 80 & 60 \\
\hline 6 & Natasha & 85 & 80 & 75 & 55 & 65 \\
\hline 7 & Suci Putri & 100 & 80 & 65 & 55 & 75 \\
\hline 8 & $\begin{array}{l}\text { Muhamad } \\
\text { Fajar }\end{array}$ & 100 & 60 & 70 & 85 & 65 \\
\hline
\end{tabular}

Sumber : Penelitian

2. Kriteria dan Bobot

Langkah kedua untuk menentukan kriteria yang akan dijadikan acuan nanti dalam pengambilan keputusan, yaitu $\mathrm{Cj}$.

a. Nilai Bobot Kehadiran

Nilai kehadiran terbagi atas 4 bilangan

fuzzy, yaitu :

Rendah (R) : :2

Cukup (C) : 3

Tinggi (T) : 4

Sangat Tinggi $(\mathrm{ST}) \quad: 5$ 


\begin{tabular}{ccc}
\multicolumn{3}{c}{ Nilai Bobot Kehadiran } \\
\hline Nilai Kehadiran & Bilangan Fuzzy & $\begin{array}{c}\text { Nilai } \\
\text { Bobot }\end{array}$ \\
\hline $20-40$ & Rendah (R) & 2 \\
\hline $41-60$ & Cukup (C) & 3 \\
\hline $61-80$ & Tinggi (T) & 4 \\
\hline $81-100$ & $\begin{array}{c}\text { Sangat Tinggi } \\
(\text { ST })\end{array}$ & 5 \\
\hline
\end{tabular}

b. Nilai Bobot Sikap kerja

Nilai sikap kerja terbagi menjadi 4 bilangan fuzzy yaitu :

Rendah (R)

Cukup (C)

$: 2$

Tinggi (T)

$: 3$

Sangat Tinggi (ST)

$: 4$

$: 5$

Tabel 3

Nilai Bobot Sikap Kerja

\begin{tabular}{ccc}
\hline $\begin{array}{c}\text { Nilai Sikap } \\
\text { Kerja }\end{array}$ & Bilangan Fuzzy & Nilai Bobot \\
\hline $20-40$ & Rendah (R) & 2 \\
\hline $41-60$ & Cukup (C) & 3 \\
\hline $61-80$ & Tinggi (T) & 4 \\
\hline $81-100$ & $\begin{array}{c}\text { Sangat Tinggi } \\
\text { (ST) }\end{array}$ & 5 \\
\hline
\end{tabular}

c. Nilai Bobot Kedisiplinan

Nilai kedisiplinan terbagi menjadi 4 bilangan fuzzy yaitu :

Rendah (R) : :2

Cukup (C) : 3

Tinggi (T) : 4

Sangat Tinggi (ST) : 5

Tabel 4.

Nilai Bobot Kedisiplinan

\begin{tabular}{ccc}
\hline $\begin{array}{c}\text { Nilai } \\
\text { Kedisiplinan }\end{array}$ & $\begin{array}{c}\text { Bilangan } \\
\text { Fuzzy }\end{array}$ & Nilai Bobot \\
\hline $20-40$ & Rendah (R) & 2 \\
\hline $41-60$ & Cukup (C) & 3 \\
\hline
\end{tabular}

\begin{tabular}{ccc}
\hline $61-80$ & Tinggi (T) & 4 \\
\hline $81-100$ & $\begin{array}{c}\text { Sangat Tinggi } \\
(\mathrm{ST})\end{array}$ & 5 \\
\hline
\end{tabular}

d. Nilai Bobot Prestasi kerja

Nilai prestasi kerja terbagi menjadi 4 bilangan fuzzy yaitu :

$\begin{array}{ll}\text { Rendah (R) } & : 2 \\ \text { Cukup (C) } & : 3 \\ \text { Tinggi (T) } & : 4 \\ \text { Sangat Tinggi (ST) } & : 5\end{array}$

Tabel 5.

Nilai Bobot Prestasi Kerja

\begin{tabular}{ccc}
\hline $\begin{array}{c}\text { Nilai Prestasi } \\
\text { Kerja }\end{array}$ & $\begin{array}{c}\text { Bilangan } \\
\text { Fuzzy }\end{array}$ & Nilai Bobot \\
\hline $20-40$ & Rendah (R) & 2 \\
\hline $41-60$ & Cukup (C) & 3 \\
\hline $61-80$ & Tinggi (T) & 4 \\
\hline $81-100$ & $\begin{array}{c}\text { Sangat Tinggi } \\
\text { (ST) }\end{array}$ & 5 \\
\hline
\end{tabular}

e. Nilai Bobot Kerjasama

Nilai kerjsama terbagi menjadi 4 bilangan fuzzy yaitu :

Rendah (R)

$: 3$

Tinggi ( $\mathrm{T})$

$: 4$

Sangat Tinggi (ST) : 5

Tabel 6

Nilai Bobot Kerjasama

\begin{tabular}{ccc}
\hline Nilai Kerjasama & $\begin{array}{c}\text { Bilangan } \\
\text { Fuzzy }\end{array}$ & Nilai Bobot \\
\hline $20-40$ & Rendah (R) & 2 \\
\hline $41-60$ & Cukup (C) & 3 \\
\hline $61-80$ & Tinggi (T) & 4 \\
\hline $81-100$ & $\begin{array}{c}\text { Sangat Tinggi } \\
\text { (ST) }\end{array}$ & 5 \\
\hline
\end{tabular}

3. Bobot Preferensi (W)

Langkah yang ketiga adalah menentukan bobot preferensi atau tingkat kepentingan (W) setiap kriteria. Bobot kriteria yang digunakan dalam menentukan karyawan terbaik pada PT Ringkat Teknologi Muliatama adalah sebagai berikut :

Tabel 7

Tingkat Kepentingan (W)

\section{Kriteria}

Bobot (W) 


\begin{tabular}{ll}
\hline $\mathrm{C} 1=$ Nilai Kehadiran & 0,25 \\
\hline $\mathrm{C} 2$ = Nilai Sikap Kerja & 0,15 \\
\hline $\mathrm{C} 3=$ Nilai Kedisipilan & 0,20 \\
\hline $\mathrm{C} 4=$ Nilai Prestasi Kerja & 0,25 \\
\hline C5 = Nilai Kerjasama & 0,15 \\
\hline
\end{tabular}

Sumber : Antonio dan Andrea (2008)

4. Nilai rating kecocokan setiap alternatif pada setiap kriteria.

Langkah yang keempat yaitu menentukan rating kecocokan setiap alternatif pada setiap kriteria yang telah ditentukan diatas ditunjukan pada Tabel 8

Tabel 8

Rating Kecocokan Alternatif

\begin{tabular}{cccccc}
\hline Alternatif & \multicolumn{5}{c}{ Kriteria } \\
& C1 & C2 & C3 & C4 & C5 \\
\cline { 2 - 6 } & 5 & 5 & 4 & 4 & 3 \\
& & & & & \\
\hline A2 & 5 & 3 & 5 & 4 & 4 \\
& & & & & \\
\hline A3 & 5 & 2 & 4 & 3 & 5 \\
& & & & & \\
\hline A4 & 4 & 5 & 4 & 2 & 4 \\
& & & & & \\
\hline A5 & 5 & 3 & 4 & 4 & 3 \\
& & & & & \\
\hline A6 & 5 & 4 & 4 & 3 & 4 \\
& & & & & \\
\hline A7 & 5 & 4 & 3 & 2 & 4 \\
\hline A8 & 5 & 3 & 4 & 5 & 3
\end{tabular}

5. Matriks Keputusan

Setelah mendapatkan nilai rating alternatif pada setiap kriteria di tentukan langkah kelima yaitu membuat matriks keputusan $(\mathrm{X})$ yang dibentuk dari tabel rating kecocokan dari setipa alternatif pada setiap kriteria. Nilai $X$ setiap alternatif (Ai) pada setiap kriteria $(\mathrm{Cj})$ yang sudah ditentukan

\begin{tabular}{|llllll|}
\hline 5 & 5 & 4 & 4 & 3 \\
5 & & 3 & 5 & 4 & 4 \\
5 & 2 & 4 & 3 & 5 \\
4 & 5 & 4 & 2 & 4 \\
5 & 3 & 4 & 4 & 3 \\
5 & 4 & 4 & 3 & 4 \\
5 & 4 & 3 & 2 & 4 \\
5 & 3 & 4 & 5 & 3 \\
\hline
\end{tabular}

6. Normalisasi Matriks Keputusan (X)

Langkah selanjutnya "Metode SAW membutuhkan proses normalisasi matriks keputusan (X) ke suatu skala yang dapat diperbandingkan dengan semua rating alternatif yang ada." (Sidik, 2015). Sebelum menghitung rumus normalisasi, kita perlu mengetahui nilai maksimal untuk setiap kriteria.

Tabel 9.

Nilai Maksimal Setiap Kriteria

\begin{tabular}{|c|c|}
\hline \multicolumn{2}{|c|}{ Nilai Maksimal Setiap Kriteria } \\
\hline $\mathrm{C} 1=$ Nilai Kehadiran & 5 \\
\hline $\mathrm{C} 2$ = Nilai Sikap Kerja & 5 \\
\hline $\mathrm{C} 3=$ Nilai Kedisipilan & 5 \\
\hline $\mathrm{C} 4=$ Nilai Prestasi Kerja & 5 \\
\hline C5 = Nilai Kerjasama & 5 \\
\hline
\end{tabular}

Selanjutnya mengitung normalisasi matriks keputusan dengan rumus

$$
\begin{aligned}
R i j=\frac{X_{i j}}{\operatorname{Max}_{i} X_{i j}} & \\
& \text { Tabel 10 } \\
& \text { Perhitungan Normalisasi }
\end{aligned}
$$


7. Matriks Ternormalisasi (R)

Hasil dari normalisasi matriks (Rij) membentuk matriks ternormalisasi (R).

\begin{tabular}{c}
1 \\
1 \\
1 \\
0,8 \\
1 \\
1 \\
1 \\
1 \\
\hline
\end{tabular}

\begin{tabular}{cc}
1 & 0,8 \\
0,6 & 1 \\
0,4 & 0,8 \\
1 & 0,8 \\
0,6 & 0,8 \\
0,8 & 0,8 \\
0,8 & 0,6 \\
\hline 0,6 & 0,8 \\
\hline
\end{tabular}

\begin{tabular}{cc|}
\cline { 2 - 2 } 0,8 & 0,6 \\
0,8 & 0,8 \\
0,6 & 1 \\
0,4 & 0,6 \\
0,8 & 0,6 \\
0,6 & 0,8 \\
0,4 & 0,8 \\
1 & 0,6 \\
\hline
\end{tabular}

8. Nilai Preferensi (Vi)

Langkah yang kedelapan adalah menghitung hasil akhir preferensi (Vij) diperoleh dari penjumlahan dari perkalian elemen baris matriks ternormalisasi (R) dengan bobot preferensi (W) yang bersesuian dengan elemen kolom matriks (R).

$$
\mathrm{Vi}=\sum_{j=1}^{n} \text { wi rij }
$$

$\mathrm{V}=\mathrm{W} \times \mathrm{R}$

Ket: $\mathrm{V}=$ Perfernsi

$\mathrm{W}=$ Bobot Kriteria

$\mathrm{R}=$ Matriks Hasil Normalisasi

Bobot preferensi didapat dari tabel yang telah dibuat sebelumnya di tabel 7 tabel tingkat kepentingan (W) yaitu : 5, 3, 5, 4, 3

$\mathrm{V} 1=[(0,25 \times 1)+(0,15 \times 1)+(0,20 \times 0,8)+(0,25$ $\mathrm{x} 0,8)+(0,15 \times 0,6)]=0,85$

$\mathrm{V} 2=[(0,25 \times 1)+(0,15 \times 0,6)+(0,20 \times 1)+(0,25$ $\mathrm{x} 0,8)+(0,15 \times 0,8)]=0,76$

$\mathrm{V} 3=[(0,25 \times 1)+(0,15 \times 0,4)+(0,20 \times 0,8)+$ $(0,25 \times 0,6)+(0,15 \times 1)]=0,77$

$\mathrm{V} 4=[(0,25 \times 0,8)+(0,15 \times 1)+(0,20 \times 0,8)+(0,25$ $\mathrm{x} 0,4)+(0,15 \times 0,6)]=0,66$

\begin{tabular}{|c|c|c|c|c|c|}
\hline $\mathrm{r} 1$ & $5 / 5$ & $5 / 5$ & $4 / 5$ & $4 / 5$ & $3 / 5$ \\
\hline $\mathrm{r} 2$ & $5 / 5$ & $3 / 5$ & $5 / 5$ & $4 / 5$ & $4 / 5$ \\
\hline $\mathrm{r} 3$ & $5 / 5$ & $2 / 5$ & $4 / 5$ & $3 / 5$ & $5 / 5$ \\
\hline $\mathrm{r} 4$ & $4 / 5$ & $5 / 5$ & $4 / 5$ & $2 / 5$ & $4 / 5$ \\
\hline $\mathrm{r} 5$ & $5 / 5$ & $3 / 5$ & $4 / 5$ & $4 / 5$ & $3 / 5$ \\
\hline $\mathrm{r} 6$ & $5 / 5$ & $4 / 5$ & $4 / 5$ & $3 / 5$ & $4 / 5$ \\
\hline $\mathrm{r} 7$ & $5 / 5$ & $4 / 5$ & $3 / 5$ & $2 / 5$ & $4 / 5$ \\
\hline $\mathrm{r} 8$ & $5 / 5$ & $3 / 5$ & $4 / 5$ & $5 / 5$ & $3 / 5$ \\
\hline
\end{tabular}

V5 $=[(0,25 \times 1)+(0,15 \times 0,6)+(0,20 \times 0,8)+$ $(0,25 \times 0,8)+(0,15 \times 0,6)]=0,79$

$\mathrm{V} 6=[(0,25 \times 1)+(0,15 \times 0,8)+(0,20 \times 0,8)+$ $(0,25 \times 0,6)+(0,15 \times 0,8)]=0,80$

$\mathrm{V} 7=[(0,25 \times 1)+(0,15 \times 0,8)+(0,20 \times 0,6)+$ $(0,25 \times 0,4)+(0,15 \times 0,8)]=0,71$

$\mathrm{V} 8=[(0,25 \times 1)+(0,15 \times 0,6)+(0,20 \times 0,8)+$ $(0,25 \times 1)+(0,15 \times 0,6)]=0,84$

Dibawah ini adalah tabel hasil pengujian dimana nilai awal diproses menggunakan metode Simple Additive Weighting (SAW) dan mendapatkan nilai hasil akhir dalam perhitungan seperti di atas, berikut ini tabel 11
Tabel 11

Hasil Pengujian 
Dari tabel 11 sudah jelas terlihat nilai terbesar ada pada V1 sehingga nama karyawan Ali Hidayat terpilih menjadi karyawan terbaik dengan nilai hasil akhir yaitu 0,85 .

\section{Kesimpulan}

\section{A. Kesimpulan}

Berdasarkan uraian pembahasan dari penelitian yang telah dilakukan maka kesimpulan yang dapat diambil dari skripsi ini adalah sebagai berikut:

1. Metode Simple Additive Weighting yang digunakan peneliti dapat memberikan alternatif keputusan yang terbaik dalam memutuskan karyawan terbaik.

2. Proses yang dilakukan untuk menentukan karyawan terbaik melalui perhitungan dengan metode simple additive weighting (SAW) dimulai dengan pemberian kriteriakriteria nilai kehadiran, sikap kerja, kedisiplinan, prestasi kerja dan kerjasama. Sehingga menghasilkan nilai dari masing-

\section{B. Saran} masing kriteria.

Beberapa saran yang bisa penulis sampaikan mengenai kaitan dengan penelitian yang telah dilakukan, diantaranya:

1. Sistem pendukung keputusan yang menggunakan metode simple additive weighting (SAW) untuk menentukan karyawan terbaik dapat dikembangkan dengan metode lain seperti AHP, TOPSIS dan lainnya.

2. Di dalam metode ini dibahas hanya untuk pemilihan karyawan terbaik saja. Setelah sudah terpilih karyawan terbaik, apakah didapatkan penghargaan atau berupa bonus yang juga bisa ditentukan melalui metodemetode sistem penunjang keputusan. Untuk itu penulis berharap skripsi ini dapat dikembangkan lagi agar hasilnya menjadi lebih baik.

\section{REFERENSI}

Abdillah Rahman, Implementasi Fuzzy Simple Additive Weighting (SAW) Sebagai Pendukung Keputusan Pada Beasiswa Penelitia. 2017;2(1):74-83.

Antonio Marcomini, dan Andrea Critto, 2008, Sistem Pendukung Keputusan untuk Manajemen Risiko Berbasis Web, Springer Science \& Business Media.

Arianto EY, Siahaan FB. Analisa Penilaian Kinerja Karyawan Dengan Metode Fuzzy Simple Additive Weighting Pada PT

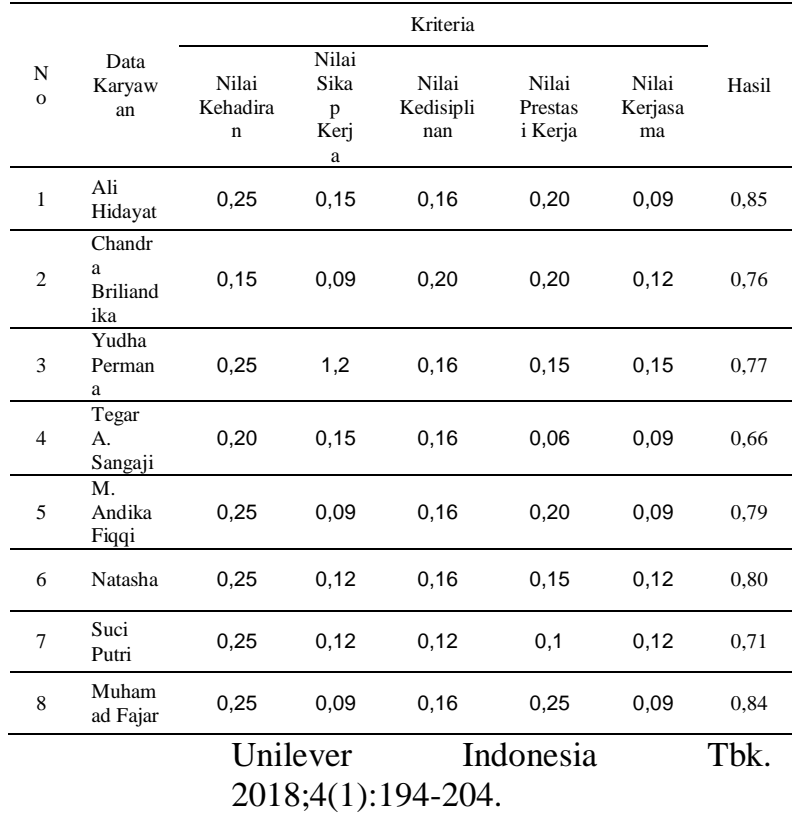

Dicky Nofriansyah (2014). "Konsep Data Mining vs Sistem Pendukung Keputusan". Edisi I, Yogyakarta, Deepublish. Hal 1-5

Fitriah A, Irfiani E. (2018) Sistem Pendukung Keputusan Pemilihan Pegawai Terbaik PT Pegadaian Jakarta Dengan Metode Simple Additive Weighting. 2018;2(2):105-114.

Frieyadie. (2016). Penerapan Metode Simple Additive Weight (Saw) Dalam Sistem Pendukung Keputusan Promosi Kenaikan Jabatan. $J$ Pilar Nusa Mandiri. 2016;12(1):37-45. http://ejournal.nusamandiri.ac.id/ejurn al/index.php/pilar/article/view/70/67\#.

Kristiyanti DA. (2017).Sistem Pendukung Keputusan Seleksi Karyawan Untuk Jabatan Tertentu Dengan Pendekatan Analisa Gap Profile Matching. Paradigma. $\quad$ 2017;19(1):20-29. http://ejournal.bsi.ac.id/ejurnal/index.p $\mathrm{hp} /$ paradigma/article/viewFile/1502/1 244.

Masri M. (2016). Penentuan Karyawan Terbaik Dengan Metode Simple Additive Weighting (PDAM Tirta Silaupiasa). JET (Journal Electr Technol. 2016;1(1):36-41.

Muhammad Ilham; Syamsul Bakhri. (2017). Pemilihan Karyawan Terbaik Di PT Sehat Bahagia Keluarga Dengan Metode Simple Additive Weighting ( Saw ). 2017;19(2):108-112. 
Murdianto H, Khairina DM, Hatta HR. (2016). Sistem Pendukung Keputusan Pemilihan Karyawan Terbaik Per Triwulan Pt.Cahaya Fajar Kaltim Pltu Embalut Tanjung Batu Menggunakan Metode Simple Additive Weighting. Pros Semin Ilmu Komput dan Teknol Inf. 2016;1(1):24-29. doi:10.17605/OSF.IO/J4YVA

Narti. (2017). Pengambilan Keputusan Pemilihan Siswa Berprestasi Menggunakan Metode AHP Dan Topsis. J Inform. 2017;4(2):198-205.

http://ejournal.bsi.ac.id/ejurnal/index.p hp/ji/article/view/2069.

Nuraeni N. (2018). Penerapan Metode Simple Additive Weighting (Saw) Dalam Seleksi Calon Karyawan. Swabumi. 2018;6(1):63-71.

http://ejournal.bsi.ac.id/ejurnal/index.p hp/swabumi/article/view/3317/2089.

Pahlevi, Adam. (2010). Membuat Aplikasi Rental Movie dengan Visual basic 6.0. Jakarta: Elex Media Komputindo.

Ritonga SK. (2013). Sistem Informasi Penilaian Kinerja Karyawan Menggunakan Metode Technique for Others Reference By Similarity To Ideal Solution ( Topsis ). Pelita Inform Budi Darma. 2013:142-147.

Romney, Marshall B., dan Paul John Steinbart. (2015), Accounting Information Systems, 13th ed. England: Pearson Educational Limited.

Sidik. (2015). Implementasi Metode Simple Additive Weighting Pada Pemilihan Toko Komputer Online Terbaik. J Pilar Nusa Mandiri. 2015;11(1):8189.

http://ejournal.nusamandiri.ac.id/ejurn al/index.php/pilar/article/download/14 $0 / 127$.

Sugiyono. (2010). Metode Penelitian Kuantitatif Kualitatif Dan R\&D. Bandung : Alafabeta

Waruwu R. (2015). Implementasi Metode Technique for Other Preference By Similarity To Ideal Solution ( Topsis ) Untuk Keputusan Pemberian Bonus
Karyawan ( Studi Kasus : Pt . Ss Finance ). 2015:85-92.

Wakhidatul Fauziah. (2015). Penerapan Metode Simple Additive Weighting Dalam Sistem Pendukung Keputusan Kelayakan Laboratorium Komputer SMP dan SMA Negeri untuk Unit Pelaksana Teknis Dinas Pendidikan Kecamatan Sukorejo . 2015;7. 